\title{
A History of the MIT Heat Transfer Laboratory
}

John H. Lienhard V

lienhard@mit.edu

W.M. Rohsenow Heat and Mass Transfer Laboratory

Department of Mechanical Engineering

Massachusetts Institute of Technology

77 Massachusetts Avenue, Room 3-162

Cambridge MA 02139-4307

Print version appeared in Heat Transfer Engineering, 24(2):3-17, 2003. 


\section{Introduction}

Heat has been studied at The Massachusetts Institute of Technology since its founding in the 1860's. Fundamental studies of heat, its measurement and transmission, were originally centered in its Physics department. Heat engineering grew out of programs in steam engines, refrigeration, and ventilation that were conducted in the Mechanical Engineering and Mining Engineering programs. Eventually, these two streams of effort were merged when the Heat Measurements Laboratory moved from the Physics department to the Mechanical Engineering Department in 1934. This lab ultimately became MIT's Rohsenow Heat and Mass Transfer Laboratory.

This paper describes the history of the MIT Heat Measurements Lab. As such, it will not follow the development of heat engineering activities in the Mechanical Engineering department (the early part of which are summarized by Mooney [1]). Also omitted are the studies of heat transmission that followed the founding of the Chemical Engineering department in 1920, including the work of W.H. McAdams and H.C. Hottel.

MIT was located in the Back Bay section of Boston until 1916, and it was sometimes called "Boston Tech". The history of the Heat Measurements Lab begins there, in the Physics department, in the primary experimental facility: the Physical Laboratory.

\section{Origins and early history of the heat measurements laboratory: 1870 to 1895}

Up to 1870 , physics was generally taught through lectures and recitations, with experiments used for purposes of demonstration. William Barton Rogers, the founder of MIT, had proposed in 1864 that the Laboratory Method of teaching physics be adopted. A plan for this was proposed by Professor Edward C. Pickering in 1869 and implemented during the fall of 1870. Professor Pickering gives a detailed account of the development and instruction in the new Physical Laboratory in the President's Report of 1876. Pickering notes that

Several of the more advanced institutions have adopted our system [of instruction] in the form in which we use it, and at many others its adoption is strongly desired.

At this time, the lab was used for "regular students, additional classes, and original research." Pickering lists some of the experiments done by regular students in the third year class, including the following.

- Expansion of Liquids, with various temperatures

- Law of Cooling, of the connection between time and temperature

- Pressure of Steam, at various temperatures

- Specific Heat, measuring first that of water

- Efficiency of Gas Burners, measuring the number of units of heat generated with a given burner per cubic foot of gas burned 
In subsequent years, the demands on the Physical Laboratory grew steadily. The lab included work on a range of physical phenomena that were of considerable importance to students majoring in engineering and other scientific disciplines, notably heat measurements, electrical measurements, and areas of chemistry. In that era, students from, say, mining engineering, performed a significant part of their lab work in the Physical Laboratories. (Electrical engineering, as Course 6, and Physics, as Course 8, were at the time a single department.) During the next two decades the Physical Laboratory grew and subdivided repeatedly, coming to occupy many separate spaces, each devoted to measurements of a particular character.

The collection of rooms composing the Physical Lab came to be known as the Rogers Laboratory of Physics in 1872. The MIT Catalog of 1885-6 describes the experimental courses in physics, noting that

...heat and electrical measurements occupy the [final] and more difficult part of the course, more advanced instruction, however, being provided in both.

It goes on to say

Original investigation is encouraged as far as possible, and the result has been a considerable number of published memoirs.

In the mid-1880's, Professor Charles R. Cross, the head of Physics, proposed that Heat Measurements become a separate laboratory. The task of constructing the lab was taken up by Professor Silas W. Holman '76,* whose previous work had included the lecture course for third-year students on Heat, as well as experimental research in the area (Fig. 1). He opened the Heat Measurements Laboratory in 1889. The President's Report for that year gives brief description of rationale for the new course:

The subject of heat measurements of various kinds, including the measurement of high temperatures, the determination of the calorific value of fuels, and similar important topics, is one of large practical importance, regarding which little information is now accessible to the student.

Professor Holman's poor health interrupted the initial development of the lab, but by 1891 the endeavor was well underway. Electric lighting was introduced to the labs in 1892, reportedly allowing "a considerable extension of working time" in all of the laboratories. Much new apparatus was acquired during 1893. No additional space was available for the Heat Measurements Lab during its first eight years, as described in the President's Report of 1896,

... and so a narrow strip was taken from one of the rooms consistuting the laboratory of electrical engineering. This room, $16 \times 29 \mathrm{ft}$, is all that we have now for this important work...The number of students taking Heat Measurements will be increased next year by the whole fourth-year class of Mining Engineering, which is likely to more than double the total number of those pursuing the subject. It is impossible to see how these needs are to be met.

* MIT traditionally indicates its alumni by the abbreviated year of their first MIT degree. Holman completed his S.B. degree at MIT in 1876. 
Holman's health interrupted his work again in 1896, with the lectures in heat being given thereafter by Mr. Charles L. Norton '93 (soon to become Professor Charles L. Norton). Holman became professor emeritus the following year, at the age of 41, and Norton took charge of the Lab for Heat Measurements.

\section{Silas W. Holman}

Silas Whitcomb Holman was born in Harvard, Massachusetts on January 20, 1856. He received his S.B. degree in Physics from MIT in 1876, and then joined the MIT Department of Physics as an Assistant. He became Instructor in Physics in 1880, Assistant Professor in 1882, Associate Professor in 1885, and Full Professor in 1893. Throughout this period, he struggled with increasingly severe rheumatoid arthritis. At length, he was defeated, becoming Professor Emeritus in 1897 and dying on April 1, 1900.

Holman's light burned brilliantly before his tragic and untimely death. He published extensively in thermal physics, and authored textbooks on precision measurement, fundamental mechanics, and other subjects. His undergraduate thesis, on the atomic theory as applied to gases, a was highly regarded effort. It was published in the Proceedings of the American Academy of Arts and Sciences and affected research in the area for several decades to follow. After joining the staff of MIT, his work included careful measurements of thermometric fixed-points at high temperature, and studies of thermoelectric and pyrometric temperature measurement, calorimetry, and the measurement of heats of combustion.

He was a much admired teacher among both his students and his colleagues: he "was born a teacher" according to Professor Cross. Even after his illness confined him to a wheel chair, "he came daily to the Institute and was constantly consulted by eager and admiring students" [2]. The reports of his department and of the Institute itself refer to him frequently in the 1880's and 1890's, in tones that gradually shift from the greatest respect to the deepest sympathy.

Holman was a student of Professor Edward C. Pickering, then head of the Physics department. Holman himself became second in command of Physics, under Professor Charles R. Cross, some years later. Among Holman's students, several went on to distinguish themselves, including: the astronomer George E. Hale '90 who organized the Yerkes and Mt. Wilson observatories and who designed the 200 inch telescope on Mt. Palomar; Charles G. Abbot '94, also an astrophysicist and later Secretary of the Smithsonian Institution; and George K. Burgess '96, later Director of the Bureau of Standards [3].

An account of Holman's life was given in 1900 by Professor Cross, who had worked closely with Holman for many years [4]. The following extract provides a sense of both Holman and his era.

Valuable as are his scientific publications, however, Professor Holman's great work was that of a teacher of young men in the laboratory. From the beginning...his influence was marked, and by his patient labors, extending through years, he brought the work that was under his charge to a high state of development. He possessed great skill in the planning of apparatus and methods, and rare judgment as to the process best suited either for purposes of instruction or for the securing of accurate scientific results. To 
the development of the Laboratory of Electrical Measurements in the Massachusetts Institute of Technology, he gave for years his best endeavors, and to him is due the success of its work. He was also placed in charge of the newly-instituted Laboratory of Heat Measurements, and though prevented by failing health from developing this as he would have chosen, he laid a solid foundation for those coming after him.

Reference has already been made to the interference of ill-health with the prosecution of the labors of Professor Holman. In fact, after reaching manhood, he was never in good health, and during almost the whole of his active life as a teacher, he struggled with a painful chronic disease, which gradually, though with some intermissions, sapped his strength. His cheerful disposition and persistence in carrying on his work were such that none but those who knew him well were aware of the fact that is was only his indomitable courage which prevented him from yielding to his malady for some years before it finally overcame him...In 1895, he finally gave up his work of instruction. For some years after this, however, though confined to his chair, and at last even deprived of sight, he continued to labor diligently, and published...tables of logarithms and [a book] on Matter and Energy...His mind was clear to the last, and his cheerfulness never forsook him. His latest years were his best ones, and his whole life was a fine illustration of the manner in which a noble spirit may rise superior to circumstances and produce the best results under conditions to which an ordinary mind would utterly succumb.

\section{Continuing development of the lab: 1897-1933}

Professor-to-be Norton energetically increased the apparatus in the lab after taking charge, contructing during 1897 a comparator for thermometers and two new coal calorimeters (one of the Berthelot type), and acquiring a Heraeus thermo-electric pyrometer "for measuring melting points, furnace and flue temperatures, and general technical work in heat measurements."

The Heat Measurements Laboratory finally received additional space in 1898, more than doubling the size of the former room. In the President's Report of that year, it is noted that the need for additional space came not from the department of physics, but from the "constantly increasing instruction which this department offers to other courses - in this instance to those of chemistry, chemical engineering, and mining engineering." This new space proved adequate for a few years, as mentioned in the 1899 report: "Notwithstanding the advanced character of the work it is at present taken by about seventy-five students, miners, chemists, and physicists. The equipment of the laboratory has increased and is now excellent, including much apparatus of original design and construction."

In 1902, Electrical Engineering became a separate department, and the some of the space freed by the removal of the Laboratory of Electrical Engineering was given over to the Laboratory of Heat Measurements. A number of photographs of the lab were taken during this time for MIT's exhibit at the 1904 St. Louis World's Fair (see Fig. 2). At this time, the lab was located in the Walker Building, at the corner of Bolyston and Clarendon 
Streets in Boston. Room 2A in the basement is identified on floor plans of the era as the Heat Measurements Laboratory. Its basement location provoked a satirical cartoon in the MIT Yearbook, Technique 1908, comparing it to Hell (Fig. 3).

The President's Report of 1903 describes, with a pride verging on glee, the state of the expanded lab:

The original plans for the laboratory, made over fifteen years ago, have steadily been developed. Beginning with a modest equipment of one or two pyrometers, a fuel combustion bomb, and several standard thermometers and comparators, located in a very small room of the laboratory, it has three times outgrown its quarters, only now to find ample space in the former dynamo room. The equipment now comprises what is without a doubt the most complete collection of standard apparatus for heat measurements in existence for purposes of instruction and entirely sufficient for any purpose. In addition there is a large amount of original apparatus for instruction and research, especially of a technical nature.

The number of students taking the lab has increased from a half dozen in 1893 to about 200 in 1903. In 1893 a small part of the time of one assistant sufficed for the instruction then given, but now the major portion of the time of Professor Norton and the entire time of one assistant are hardly sufficient for that purpose.

The laboratory has become a standardizing laboratory in many lines of work, and has acquired a wide reputation for certain of this work. The cramped quarters hitherto occupied have prevented a more rapid growth in this direction, and it is believed that the present relief will be a great help in such work.

By 1903, the work in the Heat Measurements Lab, under Professor Norton, occupied 12 weeks of the Mechanical Engineering Laboratory course run by Professor Edward F. Miller '86. The connection to Mechanical Engineering was to grow much stronger as time went by. It is interesting to note that both Norton and Miller went on to head their respective departments: Norton headed Physics from 1922 to 1930, and Miller headed ME from 1911 until his death in 1933.

\section{Charles L. Norton}

Charles Ladd Norton (Fig. 4) received his S.B. degree from the MIT Department of Electrical Engineering and Physics in 1893, and was immediately appointed as an assistant in the Physics department. In 1895, he became an instructor, working in the Heat Measurements Laboratory. He was energetic, and the reports of his department in the following years make a number of references to his efforts to develop and expand the lab. He became an Assistant Professor of Heat Measurements, in the Physics Department, in 1900, Associate Professor in 1905, and Professor in 1910. In 1917, he changed his title to Professor of Industrial Physics.

Norton was Head of the Physics department from 1922 to 1930, and Chairman of the Faculty from 1928 to 1930 . He also served as the Director of the Division of Industrial 
Cooperation (later called the Division of Sponsored Research) from 1921 until his death on September 8, 1939.

Norton was a pioneer in fire prevention practices. He invented processes used in the manufacture of asbestos wood and asbestos shingles. These inventions became the foundation for much of the asbestos industry that evolved during twentieth century. Norton himself was President of the Asbestos Wood Company and the Asbestos Shingle Company, and he operated another company called Norton Laboratories. Norton was among the first to advocate the use of Portland Cement concrete for fireproof construction. He held more than 100 U.S. and foreign patents related to these and other technologies.

Throughout his teaching career, Norton carried on a great variety of experimental researches for the Factory Mutual Insurance Company of New England (related to fire prevention), and for other parties upon such subjects as materials used for steam pipe covering, the diffusive effect upon light of ribbed and striated window glass, corrosion prevention for iron and steel, the fuel value of peat or marsh-mud, and the development of commercial apparatus for testing the thermal efficiency of fuels [5].

Norton made many other contributions. Together with colleagues in the MIT Physics Department, he was among the first to exploit X-rays as a medical diagnostic tool, as described by R.S. Williams in 1940 [6]:

Shortly after Roentgen's discovery of the X-ray, Dr. Francis Williams of the Boston City Hospital realized its potential importance in surgical diagnosis. Norton, with Professors Cross and R.R. Lawrence, became associated with Dr. Williams in the development of the X-ray technique, using an old Crooke's tube as the only available instrument. These men carried out their teaching assignments during the day, but at night they and their homemade equipment were transported to the City Hospital to spend the night taking $\mathrm{X}$-ray pictures of patients from the accident ward.

These ideas were the subject of Norton's first published paper (of 50) in 1896.

Norton's interests were quite broad. When there was a demand for metallic magnesium during the war, Norton devised a process and constructed a plant for producing this necessary mineral, for which the U.S. had been almost wholly dependent on Germany. Norton was a consultant on acoustics during the construction of the New England Conservatory of Music, and on problems of illumination in the building of the Boston Museum of Fine Arts. And, as if all this weren't enough of a legacy, two of Norton's sons went on to become professors at MIT: John, a Professor of Physics and Metallurgy; and Charles, a Professor of Metallurgy.

\section{Laboratory thermometers}

Some of the photos of the 1904 lab show a black two-door cabinet on the wall (see Fig. 5). The cabinet was designed specifically to hold the lab's collection of specialized thermometers. It remained in the possession of the lab throughout the next century.

The thermometers in the cabinet were of the mercury-in-glass type. Many of them were designed for high-precision measurement within narrow temperature ranges. Among 
the more unique instruments was a Beckmann thermometer, ${ }^{\dagger}$ which spanned a $5 \mathrm{~K}$ temperature interval with graduations to $0.01 \mathrm{~K}$ and a reading resolution of a few millikelvin (Fig. 7). This thermometer measured about two feet $(60 \mathrm{~cm})$ in length. It obtained its high sensitivity from a mercury bulb the size of a child's thumb and a very small bore capillary tube contained within a larger diameter protective tube. The thermometer had a reservoir at its upper end into which some of the mercury could be driven by heating in order to adjust the instrument's operating range.

Many of the thermometers in the cabinet were made in the late 1800's. The faculty of the Institute during that era made a number of summer trips to Europe for the purpose of acquiring laboratory equipment. Some of these thermometers bear the maker's name and a date, as can be seen in Fig. 6. The Beckmann thermometer, for example, was made by Robert Götze at the Leipzig Glass Instrument Works near the turn of the century. These instruments represented the state-of-the-art of temperature measurement at that time.

In 2001, MIT began a campaign to eliminate mercury instruments from its laboratories, so as to comply with environmental regulations. Rather than submitting the old instruments for destruction, Professor Lienhard offered the cabinet and its contents to the MIT Museum, which quickly accepted them. A few of these magnificent thermometers were placed on display in the Museum beginning in 2002.

\section{The Heat Measurements Lab goes to Mechanical Engineering: the 1930's}

When MIT moved to Cambridge in 1916, all of the Rogers Laboratories had moved to newly constructed buildings around MIT's Great Court. The labs remained in essentially the same configuration until the early 1930's.

By then, teaching and research interests in Physics were moving steadily toward what came to be called "modern physics", and more classical or applied areas were given less emphasis. During this period, several units of the Physics department were transferred to the School of Engineering, among which the Photoelasticity Laboratory and the Heat Measurements Laboratory went to the Department of Mechanical Engineering.

The Heat Measurement Laboratory moved to Mechanical Engineering in 1934. The director of the lab, Professor Gordon B. Wilkes '11 (Fig. 8), also moved to Mechanical Engineering, and he brought with him a set of five courses on Heat Measurements that he had previously offered in the Department of Physics. ${ }^{\ddagger}$ Building 7, the current home of the Laboratory, opened in the mid-1930's, and the Heat Measurements Laboratory appears to have relocated to the basement of that building shortly thereafter.

The head of Mechanical Engineering at this time, Professor J.C. Hunsaker, described Wilkes' activities in the President's Reports of 1934-5 and 1935-6. In the first report, he mentions research on low temperature radiation in connection with reflective insulation, work for the American Gas Association on technologies for heating water, and work

\footnotetext{
†This type of thermometer was invented by the chemist Ernst Otto Beckmann in 1888 or 1889 in order to measure the small temperature changes found in boiling point and freezing point determinations of molecular weight.

${ }^{\ddagger}$ A separate ME course dealing with Heat Transmission had been taught by Professor Charles W. Berry since 1917.
} 
for ASTM on techniques for measuring the thermal conductivity of refractories and insulating brick at high temperature. The second report follows.

The Heat Measurements Laboratory has added photoelectric control of temperature $\left( \pm 0.01^{\circ} \mathrm{C}\right)$ to its apparatus for the determination of the rate of heat flow through insulating materials and walls. An apparatus has also been constructed for the precise measurement of the heat flow from flat surfaces. This measurement has recently become important due to the general use of reflective type insulation. The Laboratory is coöperating with the American Society of Heating and Ventilating Engineers in a revision of the Heat Transmission Tables. The close coöperation between Professor Wilkes and others of the staff giving instruction in Heat Engineering has justified the transfer of the Heat Measurements Laboratory to this Department.

The 1934-5 MIT Bulletin includes a description of the ME's Heat Measurements Laboratory:

The Heat Measurements Laboratory is equipped primarily for research in pyrometry, thermal conductivity, thermal expansion, specific heat, heat of combustion, and refractories. It is well provided with means for measuring high temperatures, and contains furnaces and kilns for use with refractories, a refrigerating unit connected to an insulated room that can be cooled to $-40^{\circ} \mathrm{C}$, and much other equipment.

\section{Gordon B. Wilkes}

Gordon Ball Wilkes succeeded Norton as Director of the Heat Measurements Laboratory in the early 1920's and continued in that position until his retirement in June 1954.

Wilkes was born in Buffalo, New York on May 13, 1889. He received his S.B. degree in Mechanical Engineering from MIT in 1911, and he immediately joined the MIT Department of Physics as an assistant in Heat Measurements. The next year, he was promoted to Instructor in Heat Measurements, a position that he held until 1918. After a three month leave of absence at the end of 1918, he rejoined the Physics Department as an Assistant Professor of Industrial Physics. Wilkes became an Associate Professor in 1924 and was promoted to Full Professor in 1930. After Wilkes transferred to the Department of Mechanical Engineering in 1934, he used the title Professor of Heat Engineering.

Wilkes was an authority on thermal conductivity and thermal expansion at high temperatures. During his tenure, the Heat Measurements Laboratory performed extensive measurements of the thermal properties of materials, developing technologies that were later commercialized by Dynatech Corporation and others. His work resulted in several new standards for the measurement of the thermal conductivity of insulations. Wilkes published about 20 technical papers on insulation and thermal radiation between 1919 and 1945. These articles appeared in such journals as J. Amer. Ceramic Soc., Ind. Chem. Engr., and ASHVE J. He was also the author of a book titled Heat Insulation (1950).

Wilkes spent many summers consulting for industry on refractories, asbestos products, reflective insulations, and thermal conductivity measurements. The companies 
with which he worked included Harbison-Walker Refractories, Norton Laboratories, JohnsManville, Knolls Atomic Power Laboratory (G.E.), and many local firms including Arthur D. Little, Inc. and Stone \& Webster.

The available records are quite silent on Wilkes' feelings toward his transfer from Physics to Mechanical Engineering.

Professor Wilkes lived in an era somewhat different from our own. His MIT biographical sketch noted that "He belongs the University Club of Boston, the Hunnewell Club in Newton, and the Portsmouth (N.H.) Yacht Club". He died on February 16, 1976 at the age of 86 .

\section{The post-war era: 1946-1955}

Several photographs taken just after the Heat Measurements Laboratory moved to Building 7 show Wilkes at work (Fig. 9). People who were associated with the lab during in the early 1950's have described Wilkes' organization of the space. Wilkes had set up experimental stations in the lab, each devoted specifically to a different type or technique of thermal measurement. The arrangement seems to have been relatively static. The Laboratory's apparatus was, however, in constant demand by companies needing physical property measurements, and Wilkes facilitated their access to it [7].

Warren M. Rohsenow has provided the following recollection of the period from 1946 to 1956 [8]:

In 1946, when I came to the Institute, Professor Wilkes welcomed me into his Heat Measurements Laboratory to do research. His laboratory was mainly a teaching laboratory associated with his three-hour lecture course on heat measurements. This was an elective course for anyone in the Institute but taken mostly by mechanical engineering students. He had a wellorganized laboratory with various experiments permanently set up around the lab. There were experiments on natural convection with four cylinders of the same diameter but at different temperatures and another with four cylinders of different diameters but at the same temperatures. He also had experiments that would measure the emissivity of various surfaces showing that color was less important than the surface finish. For example, the varnish coating on a white painted surface had a very high emissivity, but a plain white surface had a low emissivity. Many other surfaces were measured. There were many other experiments set up and ready to use in the laboratory. Aiding in the construction and operation of these experiments were Lou Vianey, an instructor, and Ed Hartel, a mechanic. Also, Milt Raymond was a designer and mechanic on the boiling research project that I brought into the laboratory.

Prior to the war, not a great deal of research was sponsored with outside money. During the war, many research projects appeared throughout the Institute. After the war, in 1946, outside research support money was relatively easy to get. Professor Wilkes had a small amount of outside research money for thermal conductivity of insulation and heat resistance of radioactive insulation. I asked him why he didn't do heat transfer research 
in a broader sense. He responded that doing heat measurements in his laboratory did not compete with the heat transfer research done by his friend Bill McAdams in the Chemical Engineering department.

Before I made any proposals for outside research money Professor McAdams offered to have me take over the research project on high-pressure forced convection boiling water, which was sponsored by Capt. Rickover who headed the nuclear submarine project of the Navy. Naturally, I said yes and told Mac I would love him for life! John Clark was the project leader on this project. As a consultant to the Oak Ridge Gaseous Diffusion plant, I used this data to redesign the cooling system at Oak Ridge from an all liquid system, which Manson Benedict designed in a hurry during the war, to an evaporating/condensing cooling system. This was a very much less expensive cooling system.

In 1956, I took over direction of the laboratory when Professor Wilkes retired. At that point we changed the name to the Heat Transfer Laboratory, which was a better description of the work being done in the laboratory at that time.

\section{The Heat Transfer Laboratory: 1956 to 1992}

Wilkes retired in 1954, and Professor Warren M. Rohsenow became lab director in 1956 (Fig. 10). The lab's name was changed to the Heat Transfer Laboratory, in reflection of a substantial change in the philosophy of the work. Within three years of Wilkes' retirement, most of the former heat measurement stations were gone. Experimental apparatus was now built in response to the needs of specific research projects. The technologies of the various heat measurement systems were taken up by companies run by MIT faculty and alumni.

Wilkes had been working essentially alone in the Heat Measurements Laboratory, but the Heat Transfer Laboratory operated as a multi-investigator facility. John A. Clark, who started his graduate studies in 1948 on Rohsenow's first boiling project, became a faculty member in the lab after completing his ScD. He continued in the lab until about 1960. (Clark later joined the faculty of the University of Michigan.) Professor Peter Griffith (ScD '56) joined the faculty in 1956, having worked in the lab during the early 1950's. Rohsenow and Griffith, and their collaborators, conducted substantial and groundbreaking research in boiling and two-phase flow for many years thereafter. Other faculty who were working in the lab at that time included Professor Richard J. Nickerson. The lab was to see many young faculty join and leave during subsequent years.

Of the faculty who remain in the ME Department, Professor Borivoje B. Mikić (ScD '66) and Professor Leon R. Glicksman ('59) joined the lab during the 1960's. Mikić was to become very well known for the work he did on contact resistance and bubble growth during this period. Glicksman became an authority on glass fiber formation and has conducted extensive research on fluidized beds for fossil fuel power generation.

Much research in the lab during the 1960's and 1970's concerned the heat transfer aspects of nuclear reactors. This work was supported by the Atomic Energy Commission and reactor vendors. Contact heat transfer between the ceramic fuel and its metallic cladding was investigated. Boiling heat transfer to flowing water under high pressure 
conditions was the subject of many theses. Various safety issues were also investigated, including water hammer, critical heat flux phenomena, and the thermal behavior of molten materials in water. Much of that experience found its way into the classroom when the Mechanical and Nuclear Engineering Departments jointly offered a course on two-phase flow and heat transfer during the 1970's and 1980's. Two graduates of Heat Transfer Laboratory went on to join the faculty of the MIT Nuclear Engineering Department: Professor Neil E. Todreas (ScD '66) and Professor Mujid S. Kazimi (ScD '73).

The lab's character as it was in the early 1960's is captured in the following narrative by Professor Todreas [9]:

In the fall of 1963, the lab's major focus was boiling heat transfer and fluid flow. Then as up to even the present, Pete [Griffith] was the only professor in residence there, always available and willing to help any student working there with a problem. Warren was the professor in charge of the lab overseeing its general operation and supervising much of the student research activity encountered. It was amazing to me what a significant feel he had for the data we each generated even though his visits to the lab were infrequent.

It was a period when Warren conducted many visiting delegates through the lab, usually delegations of researchers from labs involved in boiling/twophase activity applicable to the nuclear power field. Consequently, it was understandable that the students doing research in the lab included a steady stream of Nuclear Engineering department students. In addition to Warren and Pete, other faculty involved in the lab were Art Bergles, Jack Reynolds, and Bill Gouse.

Technicians from ME's Engineering Projects Lab built the rigs and maintained the lab infrastructure. The infrastructure needing attention was principally the two machines capable of generating current to power our heat transfer models. A set of $36 \mathrm{~kW}$ externally excited generators were the source of high power (3000 amps at \pm 12 volts ), while a surplus motor generator set provided small power needs. Of the two, the externally excited generators were the white elephants - and finicky ones at that! Our technicians spent much effort keeping those machines operable and building the flow loops and test sections which closely surrounded these generators (thereby minimizing the length of cables needed to carry the power to our test apparatus).

Warren's principal projects at that time involved two phase boiling phenomena in duct flow - a study of the post CHF regime by Bill Laverty which was a continuation of a line of theses in this area, CHF under non-uniform axial heat flux distributions that I studied, and pool boiling with liquid metals (mainly sodium) initiated by Suhas Sukhatme and followed up by Paul Marto.

Pete's projects were on two phase flow instabilities carried out by John Maulbetsch, who subsequently became a junior faculty member, and momentum pressure loss in two-phase flow by Garry Andeen.

Art Bergles' projects involved subcooled boiling in a variety of ducts conducted by Richard Dalias, Bob Lopina, an air force officer, and Mario Fiori, a naval officer. This work included studies of heat transfer enhancement, which were initiated in 1963. 
Warren Rohsenow continued as director of the Heat Transfer Laboratory until his retirement in 1985. Throughout that era, the lab remained heavily focused on phasechange research, primarily with application to energy conversion systems. Most of the research studies were summarized in laboratory reports, which generally preceded technical papers. Distributed widely to the US and overseas organizations, these reports numbered over 80 from the time of the first report in 1951 to the late 1980s.

\section{Warren M. Rohsenow}

Warren Max Rohsenow received his bachelor's degree in mechanical engineering at Northwestern University in 1941. He earned his M.Eng. and D.Eng. Degrees at Yale University in 1943 and 1944, respectively. He was an active member of the MIT faculty from 1946 to 1985.

Professor Rohsenow's fundamental and applied research touched in nearly all modes of heat transfer became highly respected throughout the world. His work had a strong and lasting focus on thermal power conversion, including much research on gas turbines, regenerators, heat exchangers, nuclear reactors, and cooling-towers. He made pioneering contributions to the understanding of dispersed flow film boiling, condensation, metal-to-metal contact resistance, and two-phase flows.

His contributions to the thermal power industry began early in his career. After writing one of the first gas turbine theses, Rohsenow was assigned to the U.S. Navy Engineering Experimental Station (Annapolis, MD) to develop temperature instrumentation for the first gas turbine tested in the United States. His thesis investigated the effect of water injection on gas turbine performance, an idea that was incorporated in an operational plant about 40 years later by designers unaware of Rohsenow's early work [10].

Rohsenow's classroom teaching was noted for its strong emphasis on fundamentals and practice-oriented problems. His classroom material became the basis for the book Heat, Mass and Momentum Transfer (with H.Y. Choi), published in 1961. He authored/co-authored over 100 journal papers, as well as hundreds of conference papers and technical reports. He edited Developments in Heat Transfer (MIT Press, 1964); and was senior editor of the Handbook of Heat Transfer (1973) and its second and recently released third editions (1998).

Among Rohsenow' many honors, he is a member of the National Academy of Engineering, an Honorary Member of the American Society of Mechanical Engineers, and a recipient of both the ASME/AIChE Max Jakob Memorial Award and the ASME Medal. The complete list of his awards runs from 1951 to 2001. In addition to these direct tributes, ASME's Heat Transfer Division gives an annual award in Warren Rohsenow's name for the outstanding conference presentation on gas turbine heat transfer.

Warren was an accomplished pianist who played jazz with various ensembles at MIT. He kept a piano in his MIT office, which he would occasionally roll out into the corridor for departmental parties. He served as the Graduate Officer of the department for many, many years, and in this capacity he was familiar to most students who passed through the MIT ME department. 


\section{The Rohsenow Heat and Mass Transfer Laboratory: 1992-present}

In 1992, the Heat Transfer Laboratory was renamed in honor of Professor Rohsenow to recognize his many accomplishments and his leadership of the lab for 30 years. In recent years, the lab's research focus has shifted toward electronics thermal management and nanoscale transport. High heat flux engineering, convection, thermoelectricity, and thermal manufacturing processes are also ongoing interests of the lab.

Although the Heat Transfer Laboratory has remained in the same location over the last 70 years, its neighbors have changed with time. Originally, Building 7 , and the end of the Heat Transfer Lab, was bordered by Massachusetts Avenue on one side and the main MIT parking lot on two sides. Gradually, the space around the lab has filled in. To the north, Building 9 was added onto the end of Building 7, and in 1990, a new architecture library was attached to the side of Building 7. In the near future, a new ground floor entrance to the Institute from Massachusetts Avenue will be added adjacent to the lab. Despite this crowding, the Rohsenow Laboratory has no intention of moving or dropping its century long focus on heat - indeed, we look forward to another hundred years of transferring heat.

\section{Acknowledgments}

Much of this material is drawn from records held by the MIT Museum and the MIT Archives. All photographs are used with permission of the MIT Museum and are copyrighted to MIT. The author would like to thank Ms. Jennifer L. O’Neill of the MIT Museum for her assistance with the photographs and Museum files and Deborah G. Douglas, also of the MIT Museum, for her research into the history of the thermometers and for the photographs of them. In writing this paper, I have also drawn on the recollections of my esteemed colleagues at MIT, including Warren Rohsenow, Peter Griffith, Bora Mikić, Leon Glicksman, Neil Todreas, and Mujid Kazimi, and I am grateful for their help.

\section{References}

[1] Mooney, Mr., Historical Note on Heat Engineering in the Mechanical Engineering Department at MIT, unpublished manuscript, MIT Museum, c. 1948.

[2] Prescott, S.C., When MIT was "Boston Tech", The Technology Press (MIT), Cambridge, MA, 1954.

[3] David, T.L., and Goodwin, T.M., A History of the Departments of Chemistry and Physics at the MIT: 1865-1933, The Technology Press (MIT), Cambridge, MA, c. 1933.

[4] Cross, C.R., Silas Whitcomb Holman, Proc. Am. Acad. Arts Sci., vol. 36, pp. 553$556,1900-1901$.

[5] Miscellaneous biographical records of Charles L. Norton held by the MIT Museum, Cambridge, MA. 
[6] Williams, R.S., Charles Ladd Norton, Proc. Am. Acad. Arts Sci., vol. 74, no. 6, 1940.

[7] Faculty personnel records of Gordon B. Wilkes, MIT Archives, Cambridge, MA.

[8] Rohsenow, W.M., personal communication, June 2003.

[9] Todreas, N.E., personal communication, June 2003.

[10] American Society of Mechanical Engineers Awards and Honors Brochure, 2001 ASME Intl. Mech. Engr. Cong. and Exp., New York, November 2001. 


\section{List of Figures}

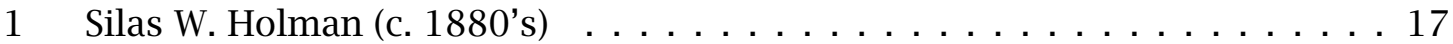

2 The lab as it appeared in 1904. . . . . . . . . . . . . . . . . 18

3 Cartoon from Technique, 1908. . . . . . . . . . . . . . . . . . 19

4 Charles L. Norton (January 1923) . . . . . . . . . . . . . . . . . . . . . 20

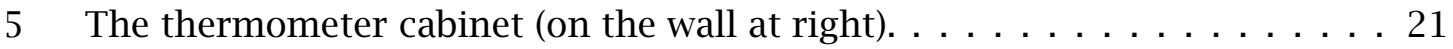

6 Details of two old thermometers. . . . . . . . . . . . . . . . . . . . 22

7 Beckmann thermometer having a $5 \mathrm{~K}$ range graduated to $0.01 \mathrm{~K}$. The coin in the foreground is a US Dime. . . . . . . . . . . . . . . . . . . . . . 23

8 Gordon B. Wilkes (March 1929) . . . . . . . . . . . . . . . . . . . . . . 24

9 Wilkes preparing refractory bricks to be tested under load at temperatures up to $1540^{\circ} \mathrm{C}$ (c. 1939). At right is a gas-fired kiln, the arch of which is a perfect catenary. . . . . . . . . . . . . . . . . . . . . 25

10 Warren M. Rohsenow (c. 1960) . . . . . . . . . . . . . . . . . 26 


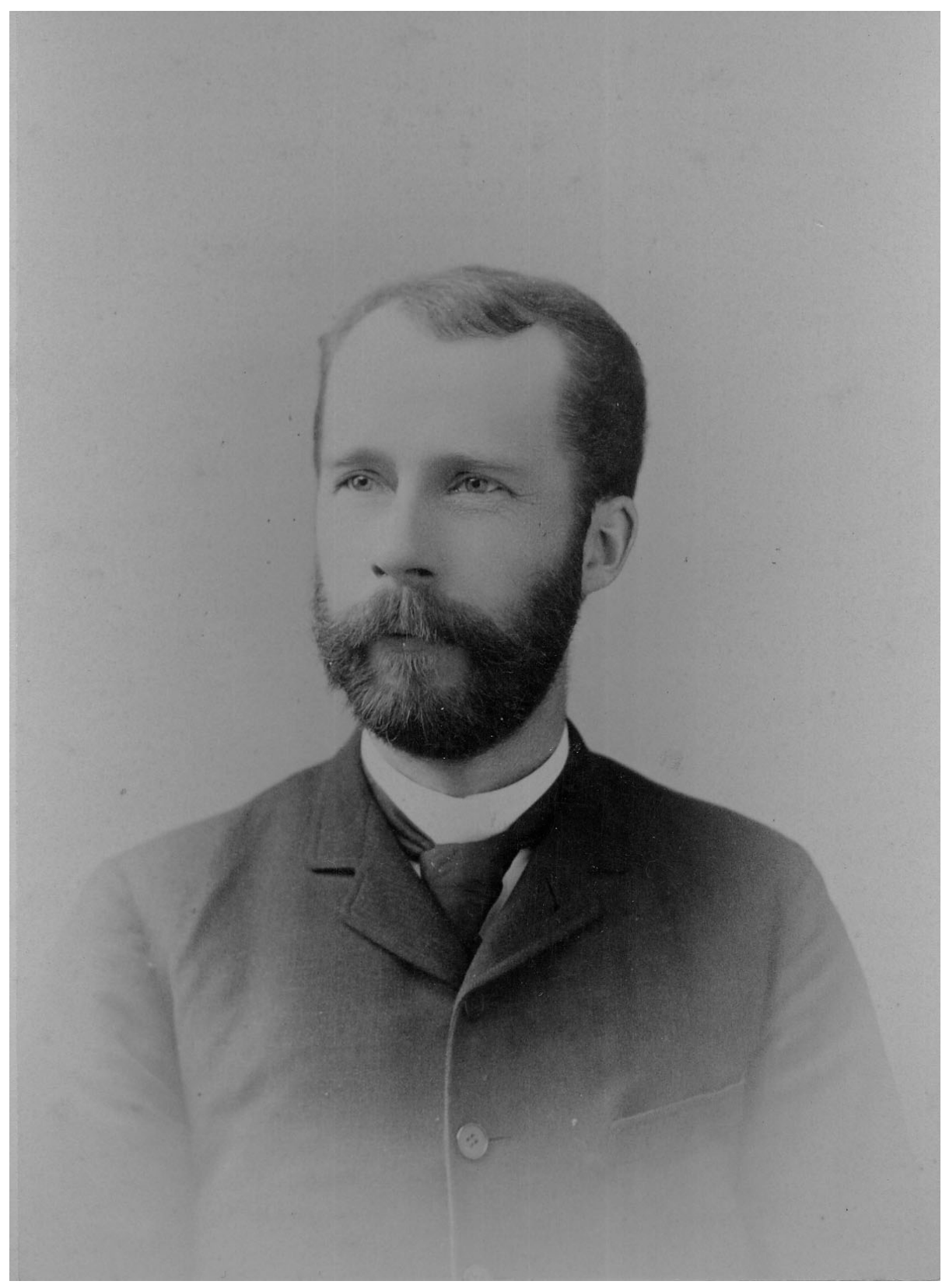

Figure 1 Silas W. Holman (c. 1880's) 

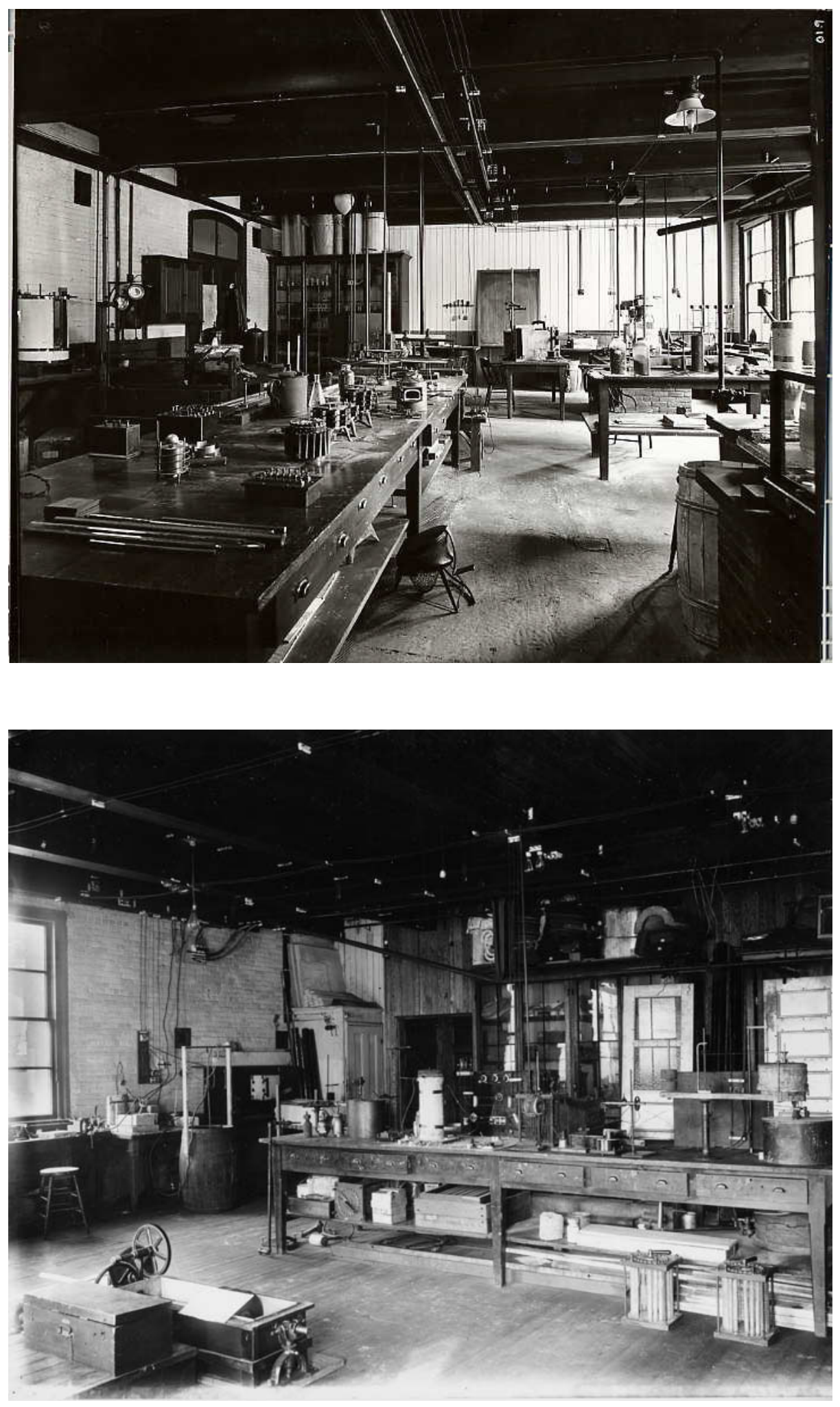

Figure 2 The lab as it appeared in 1904. 
- TECHNIQUE • 1908 .

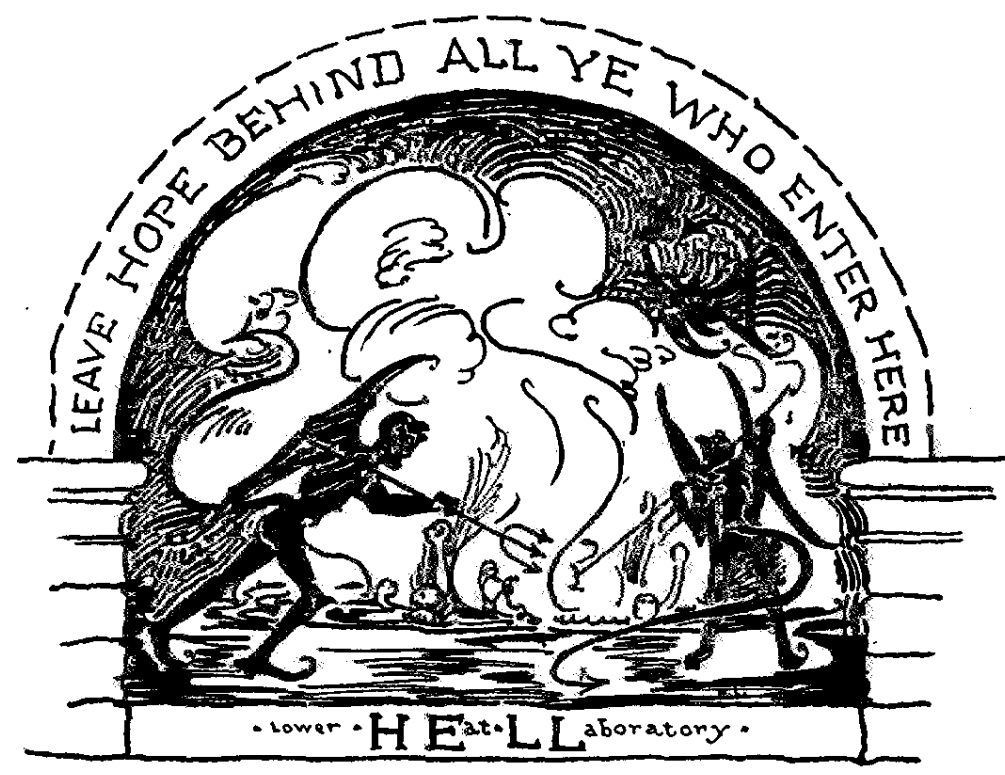

Professor Norton (in Third Year Physics): "This experiment was performed down below, in the Heat Laboratory."

Figure 3 Cartoon from Technique, 1908. 


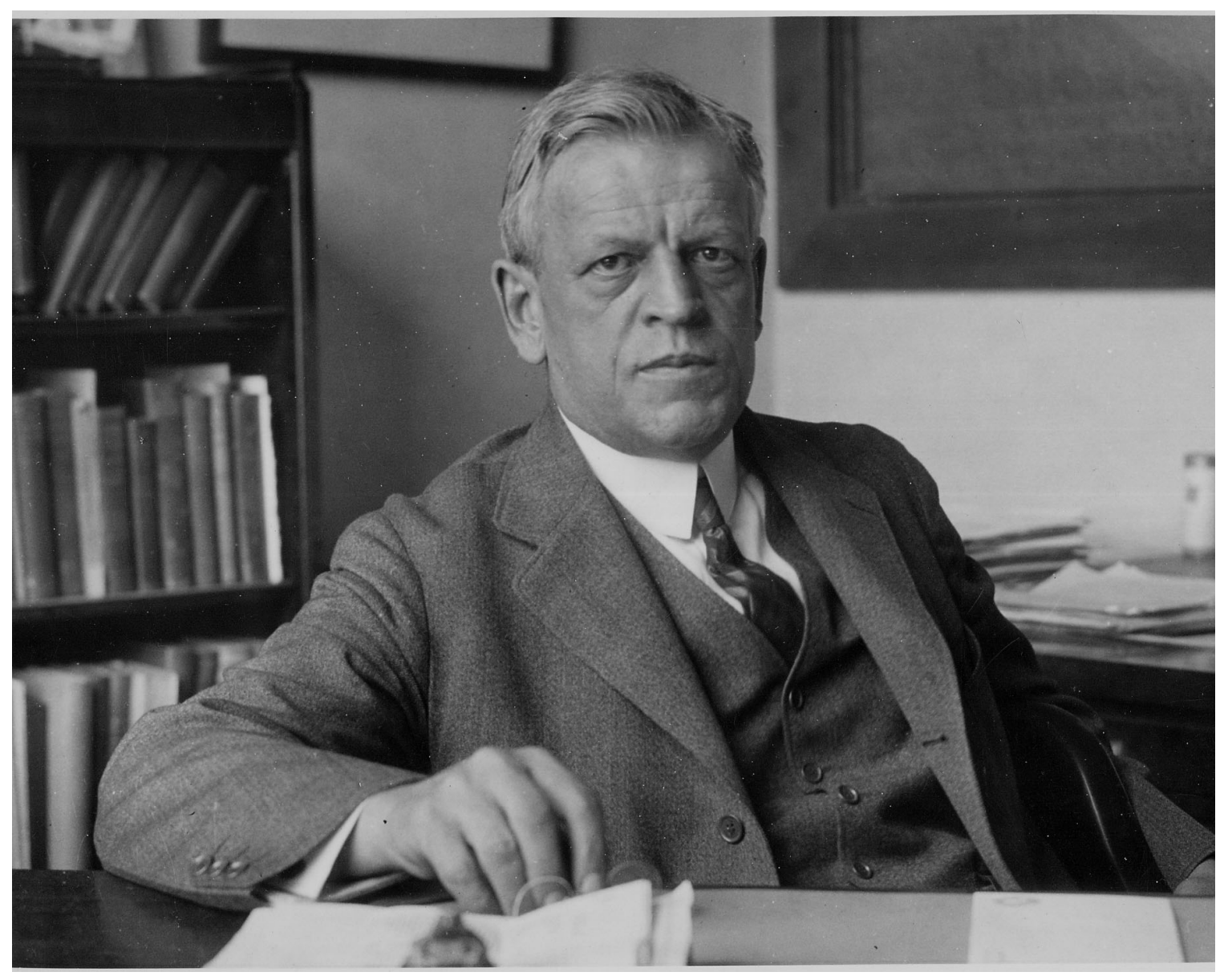

Figure 4 Charles L. Norton (January 1923) 


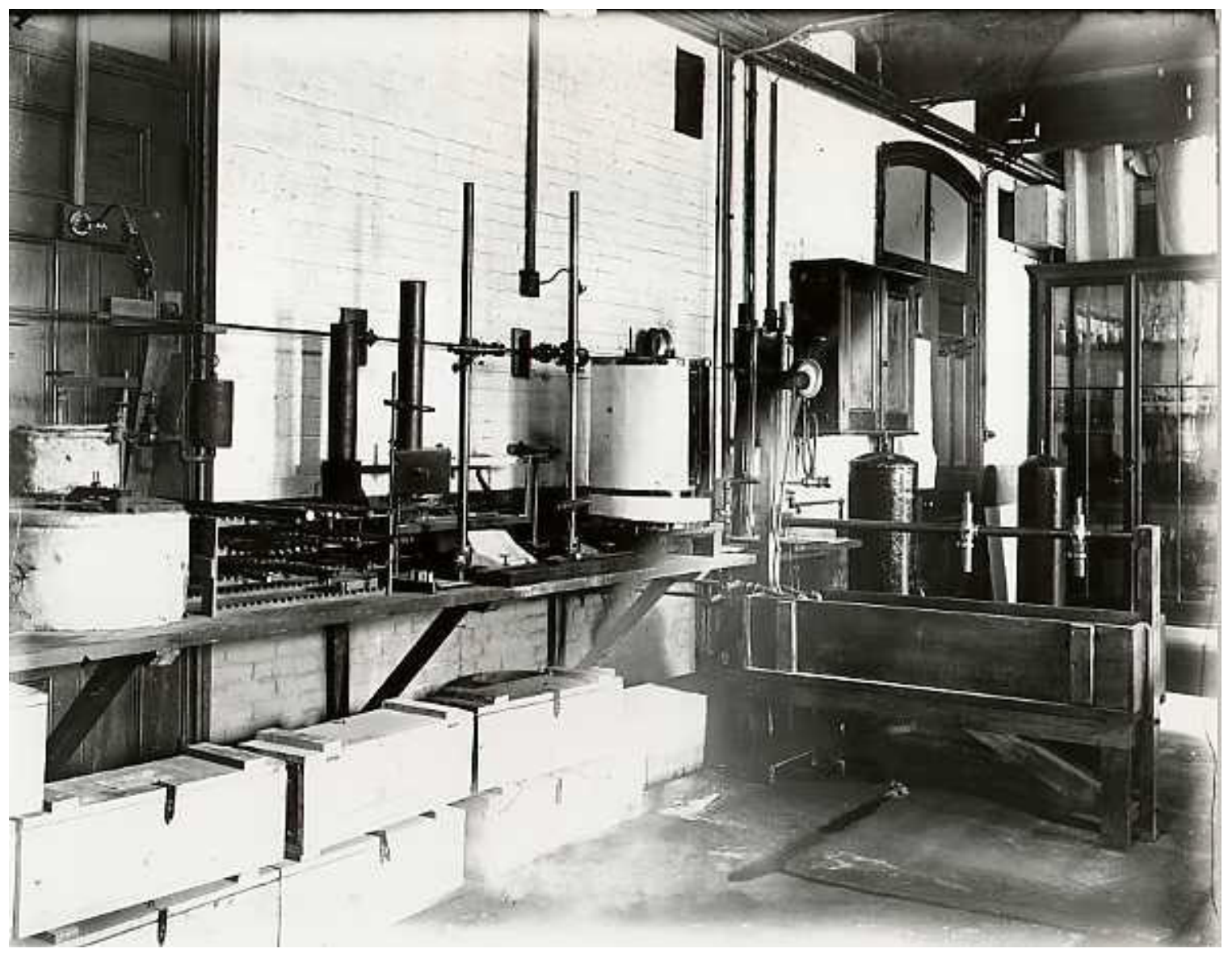

Figure 5 The thermometer cabinet (on the wall at right). 

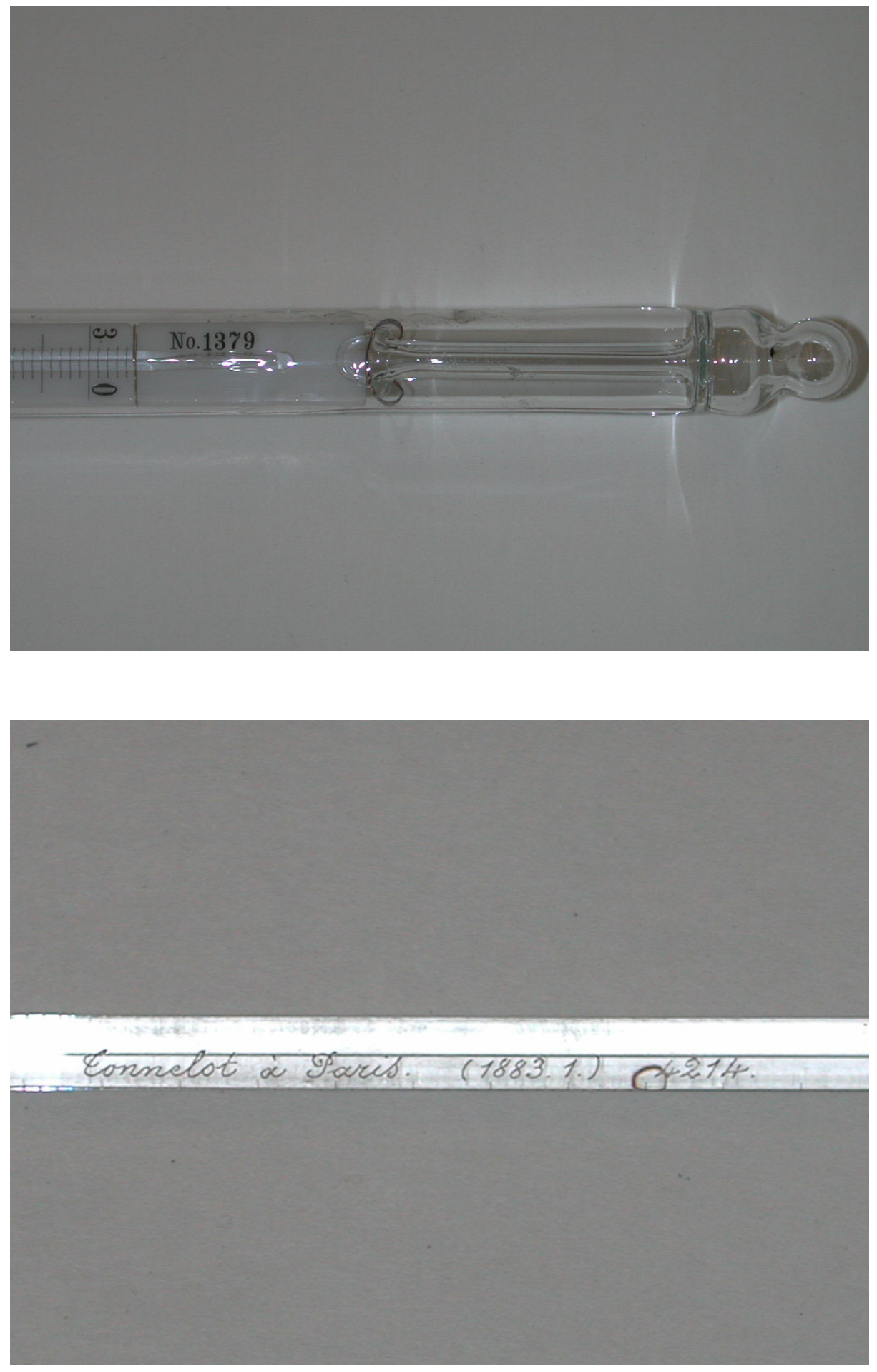

Figure 6 Details of two old thermometers. 

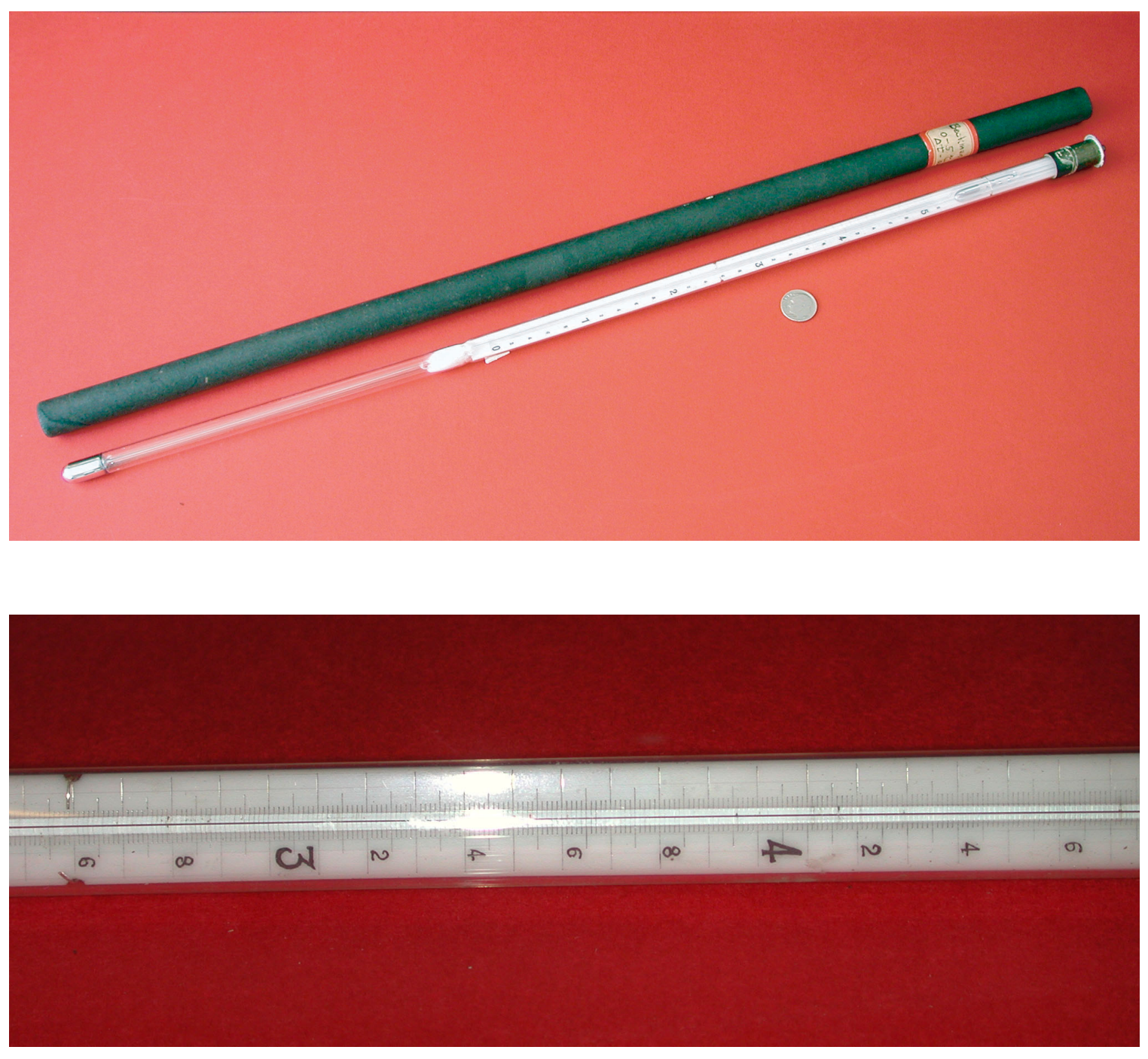

Figure 7 Beckmann thermometer having a $5 \mathrm{~K}$ range graduated to $0.01 \mathrm{~K}$. The coin in the foreground is a US Dime. 


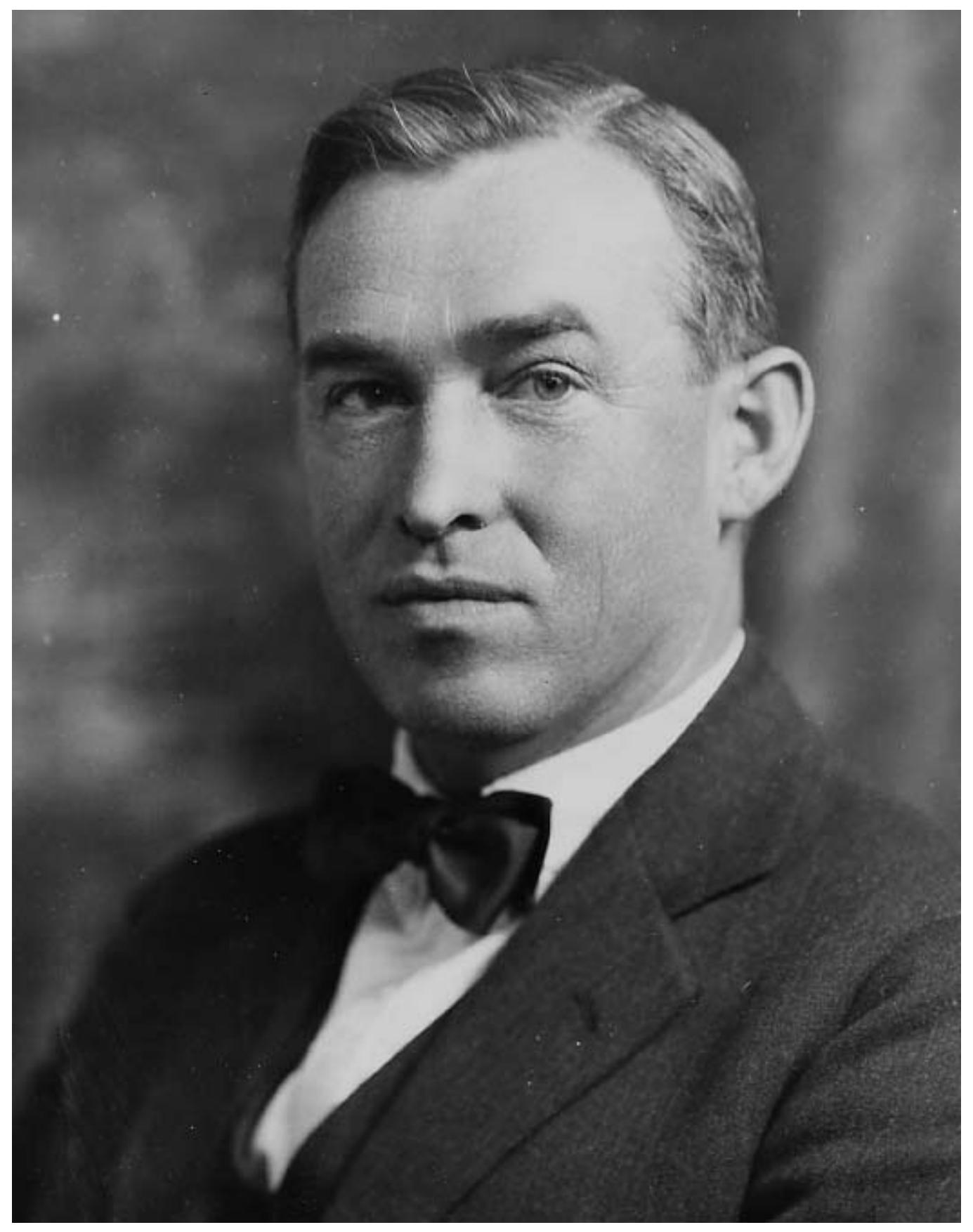

Figure 8 Gordon B. Wilkes (March 1929) 


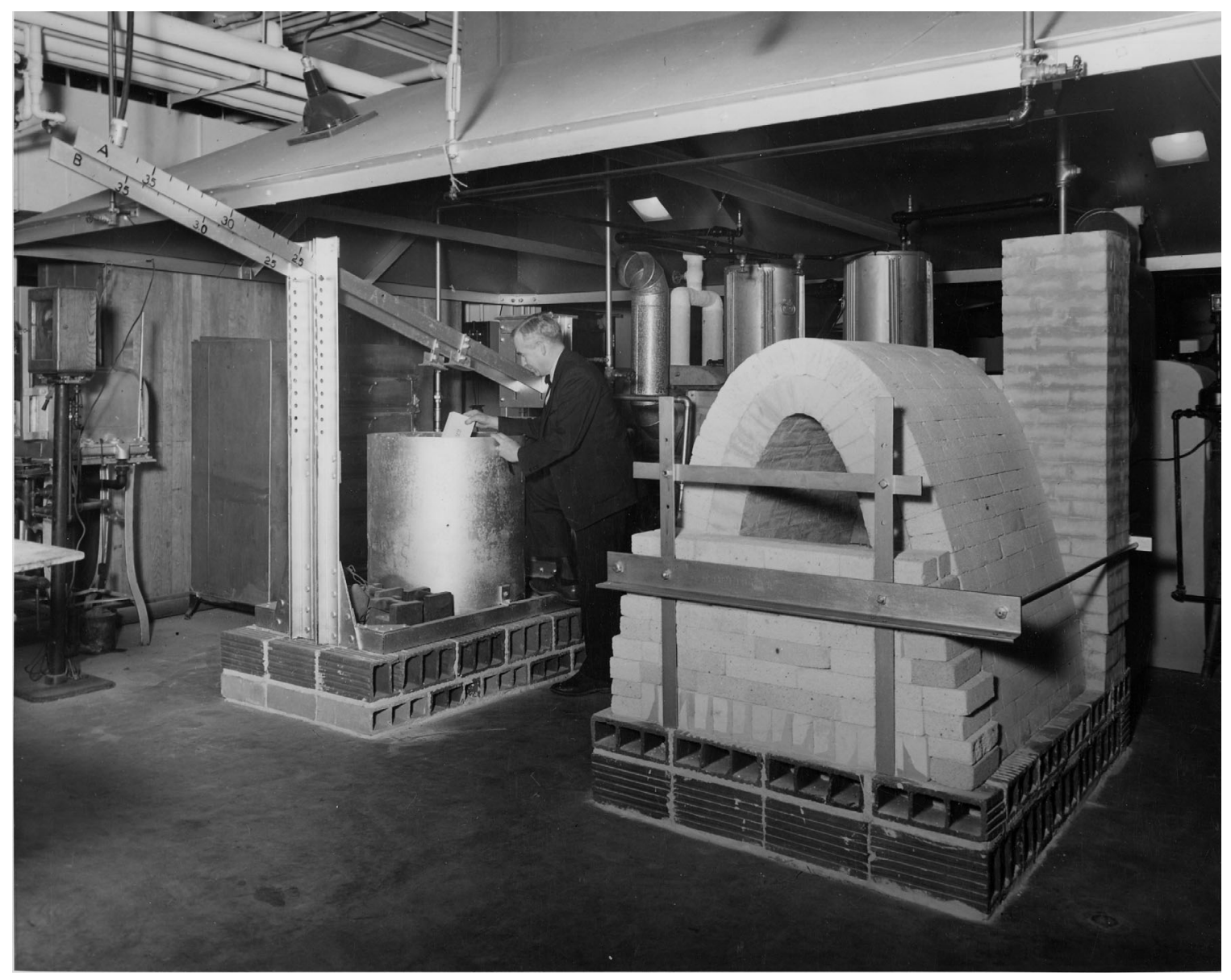

Figure 9 Wilkes preparing refractory bricks to be tested under load at temperatures up to $1540^{\circ} \mathrm{C}$ (c. 1939). At right is a gas-fired kiln, the arch of which is a perfect catenary. 


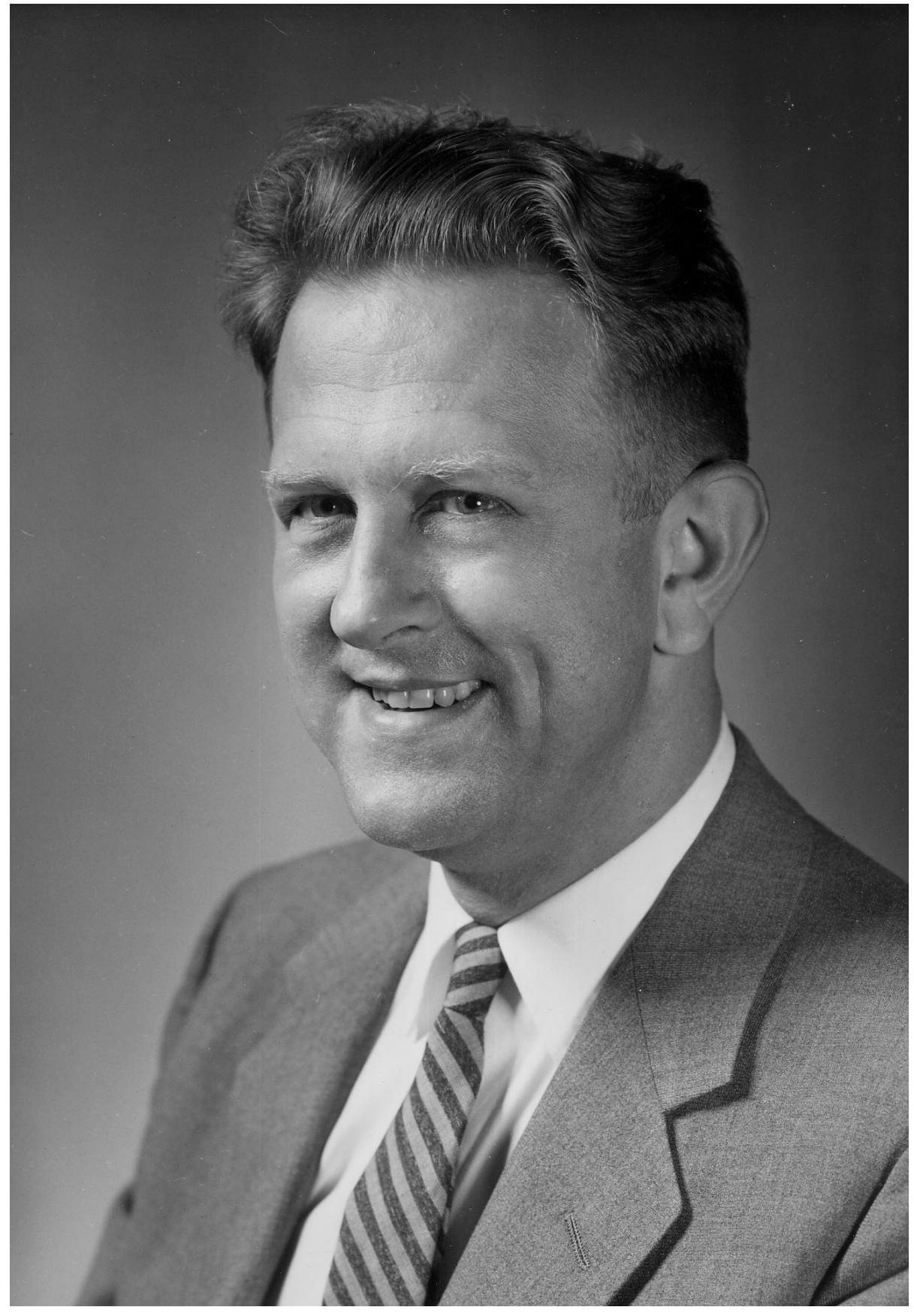

Figure 10 Warren M. Rohsenow (c. 1960) 